\title{
Genotype-Phenotype Relationships in a Mouse Model for Human Small-Cell Lung Cancer
}

\author{
J. Calbó, R. Meuwissen, E. van Montfort, O. van Tellingen, and A. Berns \\ Division of Molecular Genetics and Centre of Biomedical Genetics, The Netherlands Cancer Institute, \\ 1066 CX, Amsterdam, The Netherlands
}

\begin{abstract}
Lung tumors are usually classified into small-cell lung cancer (SCLC) or non-SCLC (NSCLC) depending on their pathological and histological characteristics. SCLC is defined not only by its characteristic neuroendocrine differentiation, aggressiveness, and metastatic potential, but also by a specific set of genetic aberrations, including the loss of the tumor suppressor genes p53 and Rb1 and the amplification of any member of the Myc family of oncogenes. We have previously described a mouse model of SCLC by somatic conditional disruption of $\operatorname{Trp} 53$ and $R b 1$ genes that closely resembles the human condition. Based on the possibility to study early tumor lesions and to culture and subclone progressed tumors and metastases, we discuss here a strategy to define genotype-phenotype relationships that can explain the underlying biology of lung neuroendocrine tumors. We have found that tumors may be constituted by genetically variant cell populations, which might represent different progression stages. Interestingly, we observed L-myc amplification and Ascl-1 expression in those populations showing neuroendocrine differentiation. Non-neuroendocrine cell populations from the same tumors did not show L-myc amplification nor Ascl-1 expression. We propose that this genetic divergence can play a relevant role in the definition of some phenotypic characteristics like metastasis potential or chemoresistance.
\end{abstract}

Since the description of cancer as a genetic disease, an overwhelming number of data have been generated which show the contribution of numerous oncogenes and tumor suppressor genes to the tumorigenic process. More recently, cancer has been defined as a differentiation disease, due to loss of proliferation constraint (differentiation) rather than acquisition of proliferative capability (Harris 2004), underscoring the relevance of undifferentiated progenitor cells carrying specific mutations that drive tumorigenesis. Conforming to this concept, "cancer stem cells" (CSC) have been observed in tumors of different origins. These cells have the ability to self-renew and to give rise to more differentiated cells that constitute most of the tumor mass, thus dictating the phenotype, metastatic properties, and response to therapy. However, the link between CSC and normal tissue stem cells is still undefined. It is unknown whether CSCs are relatively quiescent as normal stem cells, and whether tumors harbor also a "transit-amplifying" cell pool responsible for most of the proliferation. If so, classic DNA-damaging agents used in chemotherapy would only target dividing cells but would leave unaffected resting CSCs as the seeds for relapse of the tumor (Dean et al. 2005).

The current description of CSC implies that these cells have acquired and sustain a complete set of mutations responsible for the tumorigenic properties. In other words, epigenetic control rather than additional genetic changes distinguishes CSC from differentiated tumor cells, as also happens in normal tissues. In this concept, the tumor mass is an end point in which additional genetic and epigenetic changes occurring beyond the CSC or transit-amplifying compartment do not contribute to tumorigenesis but rather represent background noise. Moreover, the consideration of CSCs as the tumor seeds runs the risk of underestimating the role of less progressed cells in the biology of the tumor.

Tumorigenesis is a selective process in which the initial growth-promoting mutations can largely determine the tumor characteristics. Mitogen-independent proliferation, escape from apoptosis, survival in hypoxic conditions, or increased detoxification efficiency are likely selected for in the primary tumor mass. However, it is less clear how this selective process occurring in the primary tumor would yield genetic changes needed for metastasis. One might argue that alterations facilitating distant spread and growth occur early in tumor progression because of other selective advantages relevant for primary tumor growth. In this case, metastasis-predisposing genes would belong to the classically defined oncogenes and tumor suppressor genes (Bernards and Weinberg 2002). This is in agreement with the detection of poor-prognosis expression signatures in primary tumors that predict a high risk of metastatic spread (van de Vijver et al. 2002; van 't Veer et al. 2002; Ramaswamy et al. 2003). Another possibility is that rare cell populations, sporadically acquiring new genetic aberrations, have an increased ability to metastasize. That would explain why cells derived from metastases have repeatedly been shown to be more metastatic than the bulk population of cells from primary tumors. This is supported by observations that different subpopulations of cells with distinct metastatic potential and target-organ preference can be identified in a human breast cancer cell line both by in vivo selection and by in vitro subcloning (Kang et al. 2003; Minn et al. 2005).

Interestingly, those highly predisposed variants also share the "poor prognosis" signature but show in addition a specific set of expressed genes determining organ preference and/or metastatic potential. Therefore, both models 
appear to be true: There is a general predisposition but also the need for additional changes that may affect more or less rare cell populations of the primary tumor (Hynes 2003).

From the observation that most sporadic tumors are phenotypically heterogeneous, we hypothesize that some phenotypic characteristics might be due to the presence in tumors of genetically variant cell populations representing different evolutionary (progression) steps. Such genetic heterogeneity would give the tumor the opportunity to adapt to new situations (plasticity), required for invasion, metastases, and resistance to chemotherapy or radiotherapy.

One good example illustrating this possibility is the case of relapsed SCLC. Primary and metastatic SCLC are known to be very sensitive to chemotherapy, but drug-resistant relapses occur almost invariably. In addition, some relapsed tumors show clear transdifferentiation, resulting in NSCLC features (Brambilla et al. 1991; Kraus et al. 2002). SCLC tumors are also highly metastatic, producing distant nodules in liver, adrenal glands, brain, and bone. It is worth noting that little is known about the premalignant lesions from which SCLC originates, as patients mostly present with advanced, metastatic disease. Focusing on a unique animal model for SCLC and taking into consideration the likely heterogeneity of tumors, we present here a strategy to establish relevant genotypephenotype correlations, which can help in understanding the salient features of the underlying tumor biology.

\section{SCLC}

Lung cancer is currently the leading cause of cancer deaths worldwide, with a higher morbidity than breast, pancreatic, prostate, and colorectal cancers combined (Landis et al. 1999). SCLC is a histopathologically defined subset of lung cancers formed by small cells with scarce cytoplasm and molded nuclei, showing neuroendocrine (NE) differentiation, and accounts for almost $18 \%$ of all lung tumors. Due to the high proliferative and metastatic potential, but especially to the almost certain recurrence after chemotherapy, the 5-year survival rate for SCLC is around 5\% (Worden and Kalemkerian 2000). In contrast, $80 \%$ of lung tumors show markers of nonneuroendocrine epithelial differentiation, including adenocarcinomas, squamous cell, bronchioalveolar, and large-cell carcinomas, classified altogether as NSCLC. SCLC and NSCLC show major differences in histopathological characteristics that can be explained by the distinct patterns of genetic lesions found in both tumor classes (Zochbauer-Muller et al. 2002). As an important example, oncogenic mutations in Ras proteins are exclusively found in NSCLC tumors, whereas amplification of L-myc (MYCL1) and N-myc (MYCN) genes is exclusively observed in SCLC (Table 1) (Meuwissen and Berns 2005). C-myc gene (MYC) amplification has been observed in both NSCLC and SCLC, but the overall $M Y C$-family amplification is significantly more frequent in SCLC (20-35\%) than in NSCLC (5-20\%) (Richardson and Johnson 1993). Also intriguing is the tumor-type specificity observed in mutations affecting the $\mathrm{p} 16^{\mathrm{INK} 4 \mathrm{a}} /$
Table 1. Major Genetic Aberrations in Lung Cancer

\begin{tabular}{|c|c|c|c|}
\hline & & $\underset{\%}{\text { SCLC }}$ & $\underset{\%}{\mathrm{NSCLC}}$ \\
\hline$M Y C$ family & amplification & $20^{\mathrm{a}}-35^{\mathrm{b}}$ & $5^{\mathrm{a}}-20^{\mathrm{b}}$ \\
\hline$M Y C L 1$ or $M Y C N^{c}$ & amplification & $20^{\mathrm{a}}-20^{\mathrm{b}}$ & $<3^{\mathrm{a}}-0^{\mathrm{b}}$ \\
\hline$R A S$ & mutations & $<1$ & $15-20$ \\
\hline$E G F R$ & mutation & - & 20 \\
\hline$R B 1$ & LOH mutations & $\begin{array}{l}70 \\
90\end{array}$ & $\begin{array}{c}30 \\
15-30\end{array}$ \\
\hline TP53 & LOH mutations & $\begin{array}{c}75-100 \\
75\end{array}$ & $\begin{array}{l}60 \\
50\end{array}$ \\
\hline $\begin{array}{l}\text { INK4a } \\
\text { p16 } 6^{I N K 4 a}\end{array}$ & LOH mutations & $\begin{array}{c}50 \\
20-50\end{array}$ & $\begin{array}{l}70 \\
<5\end{array}$ \\
\hline 3 p chromosomal regi & gion $\mathrm{LOH}$ & $90-100$ & $70-80$ \\
\hline
\end{tabular}

CycD1/CDK4/RB1 pathway. Inactivation of this pathway is found in virtually all tumor types; despite the mutual exclusiveness of the mutations in these genes, alterations in pl6INK4a, CycD1, or CDK4 are most commonly seen in NSCLC, whereas $R B$ gene inactivation is a typical feature for SCLC (Zochbauer-Muller et al. 2002; Fong et al. 2003). More than $90 \%$ of SCLCs harbor abnormalities in the RB protein (Reissmann et al. 1993; Dosaka-Akita et al. 1997) and rarely show allelic loss, mutation, or promoter hypermethylation of P16INK $4 \mathrm{a}$ (Fong et al. 2003). On the other hand, TP53 missense mutations are found in $75 \%$ of SCLC and $50 \%$ of NSCLC (Toyooka et al. 2003). In SCLC, p53 loss is frequently accompanied by elevated Bcl-2 and reduced Bax protein levels (Brambilla et al. 1996). Loss of other tumor suppressor genes might be relevant in the early progression steps, as recurrent chromosome losses do occur. Especially frequent in SCLC is loss of heterozygosity (LOH) of the $3 \mathrm{p}$ chromosome region, containing putative tumor suppressor genes like FHIT, RASSF1, SEMA3B, FUS1, and $R A R \beta$.

Deregulation of the external, environmental signals that stimulate or constrain the proliferation of cells is another typical feature of cancer cells. By up-regulating growth factor receptors and their ligands, cancer cells can provide themselves with autocrine or paracrine loops facilitating tumor growth (Maulik et al. 2003). In SCLC, frequent hyperactivation is observed of the autocrine loop composed by gastrin-releasing or other bombesin-like peptides (GRP/BN) and their coupled receptors (GPCR) (Fathi et al. 1996; Rozengurt 1998). However, the mechanism of activation is not known, as no mutations or amplifications have been detected for GRP or its receptor (Forgacs et al. 2001). On the other hand, autocrine signaling involving receptors for tyrosine kinase appear to be more relevant in NSCLC. For instance, the neuregulin receptor ERBB-2 is aberrantly expressed in 30\% of NSCLC, and the epidermal growth factor receptor (EGFR, ERBB-1) is mutated or overexpressed together with its ligands in a substantial fraction of NSCLC, serving as an appealing target for therapeutic intervention (Paez et al. 2004). 
In summary, from the point of view of genetic alterations, SCLC and NSCLC are two markedly different entities, as also reflected by their histological and pathological differences. It is still an unsolved question whether this set of specific genetic changes determines the tumor phenotype or whether the transformation of different target cells drives development of distinct lung tumors. Mouse models can serve as an important tool to answer this question as well as to help to assess the contribution of different aberrations to the tumorigenic process.

\section{STRATEGY TO DEFINE GENOTYPE-PHENOTYPE CORRELATIONS}

Mouse models for human cancer have proven to be of great value in the understanding of the underlying tumor biology. Especially, transgenic models facilitate the study of the contribution of oncogene activation or tumor suppressor gene loss to the tumorigenic process. The idea is simple: Introduction of genetic lesions found in specific subsets of human cancer in the mouse may result in the development of tumors with a similar phenotype. Given that most genetic alterations driving human tumorigenesis are sporadic and somatic, the more we can reproduce this loco-temporal tumorigenic process, the closer the mouse model will likely resemble its human counterpart. Conditional transgenesis, and regulatable and lineagespecific directed expression are indispensable tools for building accurate cancer mouse models (Jonkers and Berns 2002).

Our approach to study the molecular determinants of lung tumorigenesis consists of an integrated survey of genotypic changes and phenotypic consequences (Fig. 1). The starting point is the selection of gene mutations relevant for the human disease. In the case of SCLC, we selected Trp53 and $R b 1$ loss, whereas in the case of
NSCLC, we and other investigators have introduced oncogenic $K$-Ras mutants to model lung adenocarcinoma in mice (Fig. 2) (Jackson et al. 2001; Johnson et al. 2001; Meuwissen et al. 2001). By using adenovirus-mediated somatic gene transfer of Cre recombinase, conditional Trp53 and $R b 1$ alleles can be inactivated in the lung epithelium. In this way, we mimicked the site, the time, and the sporadic fashion in which mutations occur in human SCLC. Tumors do arise with high penetrance, showing histopathological features very similar to those of the human disease (more details about this model are described below). Interestingly, targeting the same range of cells with the same Adeno-Cre vector in conditional K-RasV12 mice resulted in exclusive induction of adenocarcinoma (Meuwissen et al. 2001).

It is currently accepted that tissue stem cells are the most likely target cells, given their ability to self-renew, thereby allowing the accumulation of mutations. Substantial efforts are being made to identify these self-renewing stem cells from different tissues. In lung, different progenitor/stem cell niches have been defined, including the $\mathrm{CK} 14^{+}$cells in the epithelium of proximal airways (Hong et al. 2004), the variant Clara cells associated with NE bodies (Hong et al. 2001), and another type of variant Clara cells found in the bronchioalveolar duct junction in the distal airways (Giangreco et al. 2002). Very recently, Kim et al. have shown the presence in adult mice of a stem cell population able to repopulate damaged epithelium. These stem cells likely give rise to adenocarcinomas upon acquiring an oncogenic K-Ras mutation (Kim et al. 2005). However, much less is known about the progenitors of NE cells in the lung. It is possible, although experimental data supporting this are lacking, that the same stem cells can differentiate into both the epithelial and NE lineage. In that case, the target cell for NSCLC and SCLC would be the same. Which tumor

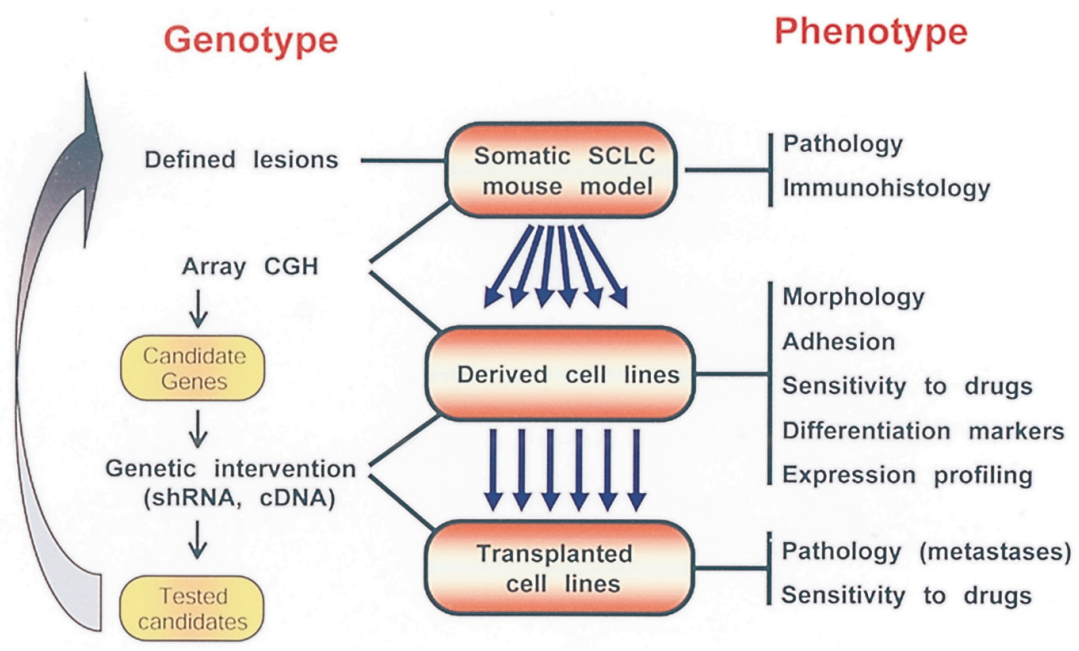

Figure 1. Strategy to establish genotype-phenotype relationships in a mouse model for SCLC. Genetic alterations observed in the human disease are mimicked in mice to initiate tumorigenesis. Tumors are studied both phenotypically (histopathology) and genotypically (array CGH). Derived cloned cell lines facilitate a more extensive study of phenotypic features, which can be matched to genetic data. Observed additional genetic alterations correlating with a specific phenotype can be further studied by genetic manipulation of cell lines. The contribution of these candidate genetic changes to the in vivo phenotype can be initially tested in an orthotopic transplantation model and finally in a spontaneous compound mouse model. 
A

B

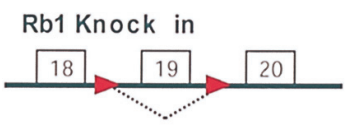

L-STOP-L K-RasV12 Transgene
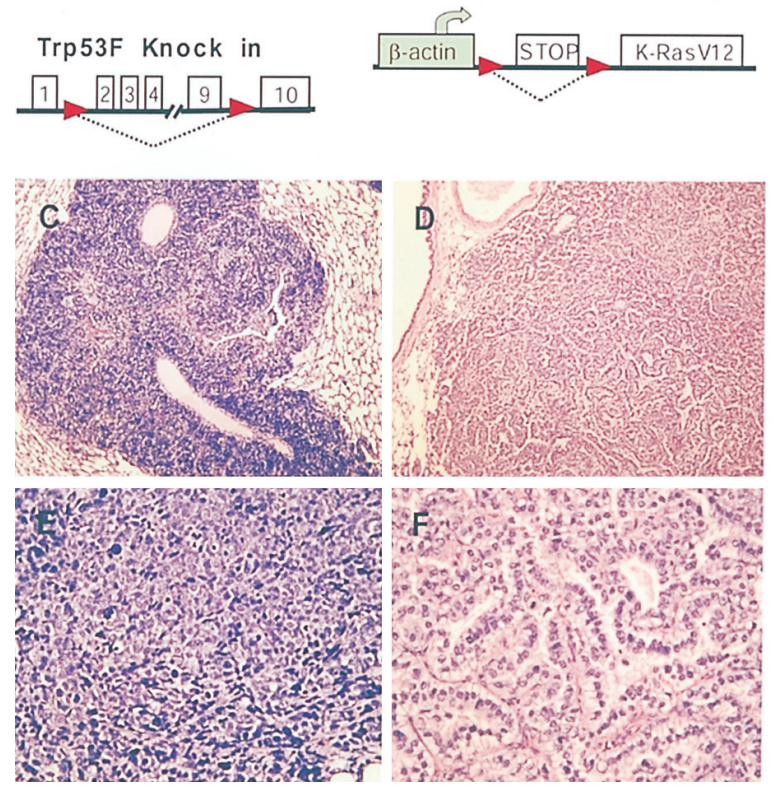

Figure 2. Induced genetic alteration determines tumor phenotype. (A) Schematic representation of $R b 1$ and $\operatorname{Trp} 53$ conditional alleles. LoxP sites (red triangles) were inserted around exon 19 of $R b 1$ and exons 2-9 of Trp53. After Cre-mediated recombination, the region between LoxP sites is removed (dotted line), resulting in loss of function. $(B)$ Schematic representation of conditional oncogenic mutant $K$-Ras allele. In this transgene, LoxP sites (red triangles) were surrounding a transcriptional STOP cassette. After Cre-mediated recombination, the region between LoxP sites is removed (dotted line), resulting in $\beta$-actin promoter-directed expression of K-RasV12 oncogenic protein. $(C-F)$ Representative hematoxylin \& eosin staining on mSCLC tumors $(C$ and $E$ ) or mNSCLC tumors $(D$ and $F)$.

arises then would depend on the genetic lesions acquired. In contrast, different progenitor cell populations could generate Clara cells and alveolar type I and II cells on the one hand and NE cells on the other hand. A NE progenitor cell has been found in bronchial epithelia that survived ablation of all cells carrying a Clara-cell-specific marker. However, it is unclear whether this cell represents a genuine stem cell or a transit-amplifying cell. The ablation of all Clara cells in mouse lung does allow only short-term survival of the mice, so the reconstituting potential of the NE progenitors could not be rigorously tested. The presence of NE stem cells in lung is supported by a study showing a similar pattern of sonic hedgehog ( $\mathrm{SHH}$ ) signaling in embryonic NE precursor cells and in a subset of SCLCs (Watkins et al. 2003). Nevertheless, the potential NE precursors in the adult lung are not well defined.

If the precursor cell for SCLC and NSCLC is not the same, this implies that particular progenitor cells can only be transformed by specific mutations, thereby contributing to the tumor-type specificity of distinct mutations. Experimental evidence using a conditional oncogenic K-RasIRESlacZ allele indirectly supports the latter, since wide expression of K-RasV12 predominantly results in an early induction of adenocarcinoma in the lung, while other tissues are largely unaffected (Guerra et al. 2003). These mouse models have clearly established a functional relationship between the initiating genetic lesions and the final phenotype of the tumors, offering unique opportunities to study these early lesions.

However, in most, if not all, cases, additional mutations are required both in man and in mouse. Cells carrying initiating mutations will acquire additional genetic alterations followed by clonal expansion, and selective outgrowth will result in the final genotype and phenotype of the tumor. Unfortunately, insight into this evolution history is still poor, mostly due to the complexity of the process and the difficulty to study precursor lesions. This is even more critical in tumors like SCLC, for which no clear premalignant stages have been defined. We can now, using well-defined animal models, look at precursor lesions and at different stages of tumor progression. The other way to learn about this evolutionary process takes advantage of the persistence of clones representative for different progression steps in the tumor. Genetic aberrations observed in these stages can be compared, and the sequence of events can be determined, indicating the order, relevance, and phenotypic consequence of frequently occurring genetic alterations.

Ideally, one would like to know the genotype and potential phenotype of each cell, or at least each distinct cell population, forming a tumor. By using linear amplification of genomic DNA, it is in principle possible to search for genomic aberrations in a single cell by array comparative genomic hybridizaton (CGH), and to establish a hierarchical clustering containing genealogical information. Using this approach, it has been recently described that breast cancer tumor cells might disseminate while harboring far fewer genomic aberrations than observed in primary tumors or in overt metastases (Schmidt-Kittler et al. 2003). This result points to the importance of less progressed tumor cell populations in establishing metastases. Derivation of several cloned cell lines from a single tumor lesion will allow us to study these genealogical relationships, but will also permit us to obtain better insight into the phenotype of each variant (Fig. 1). Expression profiles, in vitro growth characteristics, cell adhesion and migration characteristics, drug sensitivity, resistance to anoikis, in vivo tumor growth, and metastatic potential are examples of phenotypic features that one would like to match with distinct genetic aberrations. For each cell line, one can link genotype and phenotype, and then make a comparison between cells from the same tumor that share a number of genetic alterations but differ with respect to others. In this way, one can obtain information about the relevant genetic events that are responsible for a specific feature. Moreover, observed gene expression patterns can be easily reproduced and monitored in vitro by overexpressing or down-regulating genes. This will provide insight into the role of these genes in determining the phenotypic characteristics of the tumor. However, this approach is only possible when the in vivo-in vitro transition does not cause a major change in cell behavior 
or results in a strong selection for specific cell variants. One can consider an orthotopic transplantation experiment resulting in a tumor that is very similar to the primary tumor as an indication for limited culture artifacts. In addition, such study might be further complicated when tumors show a high genomic instability.

Importantly, we can reproduce in compound mutant mice some of the observed genetic aberrations and confirm their contribution to the tumor phenotype. Thus, the role of particular combinations of genetic aberrations found in variant cell populations can be studied. This will help to understand whether some of these variant populations, although relatively small, might in fact determine the prognostic features of the tumor.

Next, we describe the use of this strategy in a mouse model for SCLC developed in our laboratory, and we present initial findings illustrating both the resemblance of the mouse model to the human disease and the suitability of this approach.

\section{SPORADIC MOUSE SCLC MODEL}

We have described previously the generation of a murine model for SCLC (mSCLC) (Meuwissen et al. 2003). Somatic application of the Cre-loxP system was used to obtain lung-epithelium-specific deletion of $R b 1$ and Trp53 genes. Somatic inactivation of both $R b 1$ and $\operatorname{Trp} 53$ alleles in a broad range of proliferating lung epithelial and alveolar type II cells leads to the development of multiple tumors with a histological morphology and immunophenotype closely resembling human SCLC (Fig. 3). Within a relatively short time period after inoculation of mice with Adeno-Cre virus (6-8 weeks), we observed small foci of NE cell proliferation in the airways, which could represent the precursor lesions for dysplasias and histologically malignant lung tumors. However, NE proliferative foci were still detected in mice that already had substantial tumor load and even metastases. This might indicate that loss of Rb1 and p53 function leads to the expansion of a population of cells highly prone to SCLC development, but that additional genetic lesions are required for progression. Overt tumors, which could be observed 25-40 weeks after infection, were highly proliferative, invasive, and had a marked capacity to metastasize to liver, brain, adrenal gland, bone, and ovaries. Expression of markers for NE differentiation were observed in both primary tumors and metastases, including synaptophysin, neural-cell adhesion molecule 1 (Ncam1), Calcitonin-gene-related peptide (Cgrp), in association with high Ascl1 expression (Fig. 3). The mammalian achaete scute homolog 1 (ASCL1, HASH-1) is a basic helix-loop-helix transcription factor that determines the onset and maintenance of NE differentiation in normal pulmonary epithelial cells and also in lung tumors with NE features (Ball et al. 1993; Borges et al. 1997), and is considered a key marker for human SCLC.

To expand the study of genotype-phenotype relationships to distinct cell populations in these tumors, a number of independent cell lines were derived and characterized. All showed expression of NE markers. All these cell lines have been subcloned, and several of the obtained clonal cell lines are now further characterized by immunophenotyping, expression profiling, and array CGH. In vitro growth properties are also being studied. The initial results indicate that different subclones derived from a single tumor may have distinct phenotypes, even when genetic markers (CGH) point to a clonal origin (data not shown), and both $\operatorname{Trp} 53$ and $R b 1$ genes are biallelically inactivated in each case. The vast majority of the subclones tested show strong NE differentiation, which correlates with
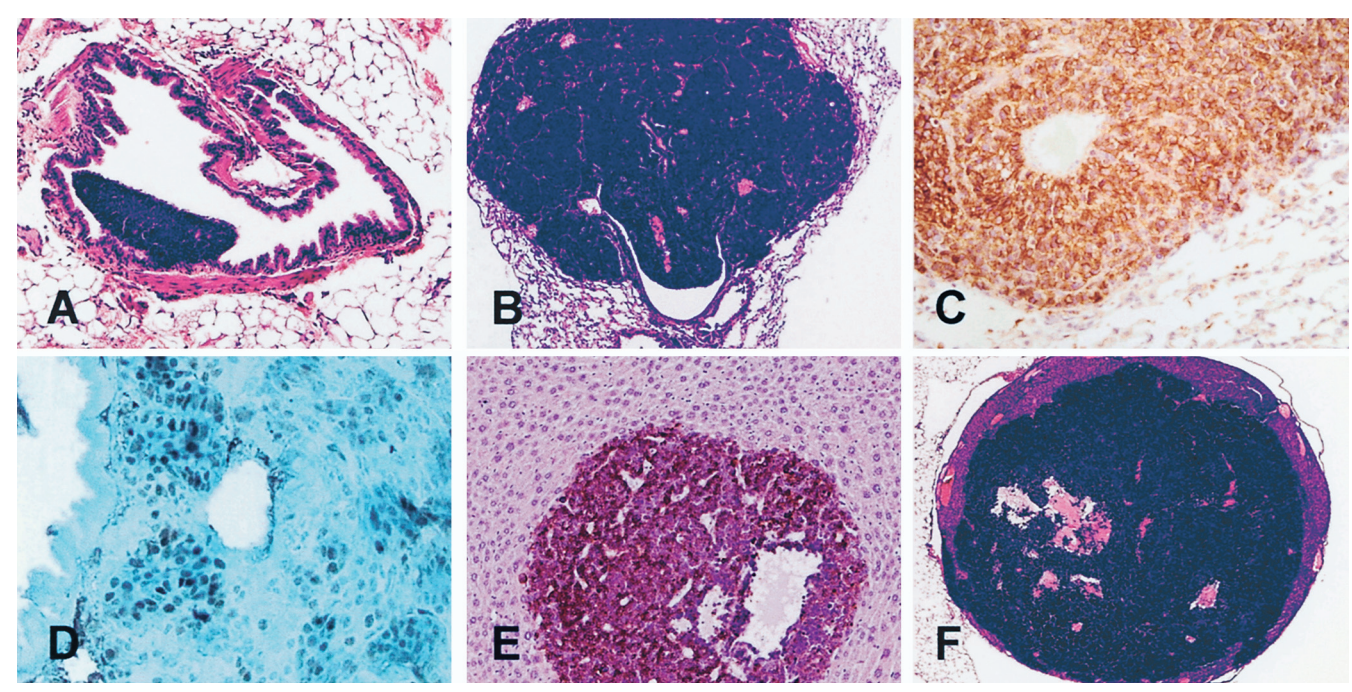

Figure 3. Histopathology of NE tumors from mice carrying $\operatorname{Trp} 53$ and $R b 1$ conditional alleles. $(A)$ Representative photomicrograph of NE proliferative foci lying in the lumen of bronchioles, visible after 8 weeks of tumor induction. $(B)$ Extensive mSCLC tumor, surrounding blood vessels and infiltrating into lung parenchyma. (C) NCAM-1 immunodetection of a mSCLC tumor, showing membrane staining. (D) Mash-1 (Ascl1) immunodetection of a mSCLC tumor, showing nuclear staining. (E) Synaptophysin immunodetection of a liver metastasis from mSCLC. Note cytoplasmic staining in tumor cells but not in liver parenchyma. $(F)$ mSCLC metastases into the ovary. (Reprinted, with permission, from Meuwissen et al. 2003 [CElsevier].) 


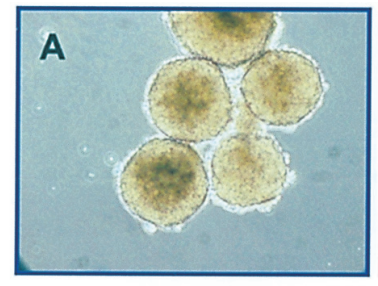

Neuroendocrine

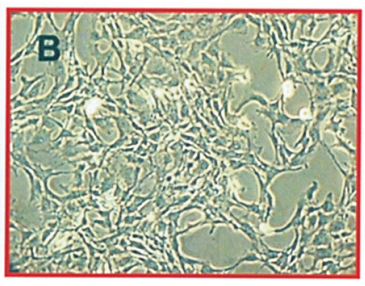

Non-Neuroendocrine
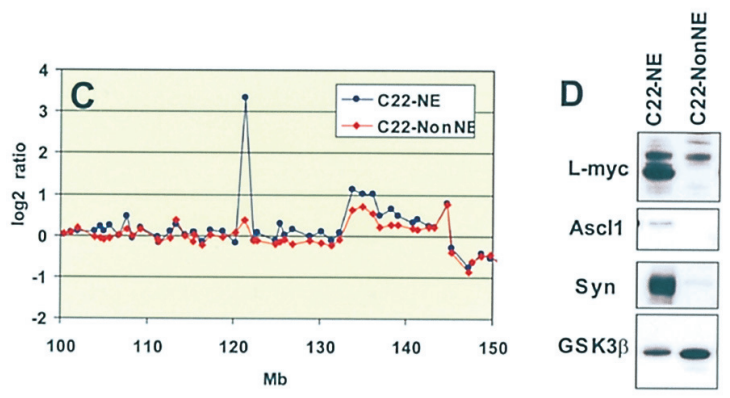

Figure 4. Comparison of distinct cloned cell lines derived from the same original tumor $(\# 22)$. $(A, B)$ Photomicrographs showing the morphology of $(A)$ NE-differentiated cells, growing in floating aggregates, and $(B)$ non-NE cells, attaching to the plate and featuring spindle-like shape. $(C)$ Array $\mathrm{CGH}$ profile from a small region on chromosome $4(100-150 \mathrm{Mb})$. NE-differentiated cells (blue line), but not non-NE cells (red line), show a high-level amplification of a BAC-clone-containing Lmycl locus. (D) Immunoblotting of L-Myc, Mash-1, synaptophysin, and GSK3 $\beta$ (loading control), showing the correlation between L-myc overexpression and NE-marker expression.

high expression levels of L-myc, N-myc, and Ascl1. These subclones grow as aggregates in suspension resembling "neurospheres." However, other subclones from the same tumors grow attached to substrate and show an expression profile clearly divergent from the NE-differentiated cells. The expression of some stem cell markers in these cells might point to the presence, in mSCLC tumors, of a population of undifferentiated cells, which could be responsible for the metastatic potential of those tumors and especially for the relapse after chemotherapy. In Figure 4, an example of the in vitro morphology of two cloned cell lines is shown. Note that both NE cells, growing in floating aggregates, and non-NE, spindle-like cells were established from the same mSCLC tumor. Some of these cloned cell lines have been orthotopically transplanted into Balb/c nude mice. Only orthotopically transplanted NE cells closely reproduce the tumor growth properties and marker expression of the original tumors. Variant, non-NE cells that lack some genetic aberrations characteristic of SCLC also do not reproduce the SCLC tumor phenotype upon orthotopic grafting, and might represent a minor subpopulation in the original tumors.

\section{INSIGHT INTO THE MOLECULAR EVENTS}

To gain better insight into the separate role of p53 and Rb1 loss in SCLC induction, mice homozygous for both the Trp53 and $R b 1$ conditional alleles were compared to mice carrying either a wild-type (wt) Trp53 allele $(\operatorname{Trp} 53 F / w t ; R b 1 F / F)$ or a wt $R b 1$ allele $(\operatorname{Trp} 53 F / F$; $R b 1 F / w t$ ) (Meuwissen et al. 2003). Our data show unambiguously that loss of $R b 1$ and Trp53 tumor suppressors acts synergistically in mouse NE tumor formation and that loss of both $R b 1$ and Trp 53 is therefore a prerequisite for NE lung tumor formation (Table 2). First, Cre-mediated biallelic deletion of Trp53 and $R b 1$ is found in all NE lung tumors from $\operatorname{Trp} 53 F / F ; R b 1 F / F$ mice. Second, NE lung tumors from $T r p 53 F / w t ; R b 1 F / F$ mice showed LOH of the remaining wild-type Trp53 allele, and third, $\operatorname{Trp} 53 F / F ; R b 1 F / w t$ mice only developed mSCLC upon loss of the wt Rbl allele; when the wt Rbl allele was retained, only adenocarcinomas ensued, similar to those found in $\operatorname{Trp} 53 \mathrm{~F} / \mathrm{F}$ mice or in $\operatorname{Tr} p 53^{-/-}$mice. In summary, complete loss of Trp53 was observed in all tumors, being an essential event for both adenocarcinoma and SCLC. In contrast, $R b l$ loss per se was unable to initiate lung tumorigenesis but was required together with loss of Trp53 for the development of NE tumors. This suggests that $R b 1$ loss permits the proliferation of cells expressing the NE differentiation program, whereas $R b l$ loss is insufficient to allow proliferation of other cell types, possibly as a result of redundancy of other pocket protein family members. Recent evidence obtained in studies in which targeted disruption was performed of either $R b 1$ alone or the three retinoblastoma-protein family members (i.e., $R b 1, p 130, p 107)$ in embryonic lung epithelium further demonstrates a specific role of $R b l$ in the determination of NE cell fate (Wikenheiser-Brokamp 2004). These results also show marked functional redundancy of the pocket proteins in epithelial cell lineages, which could explain, at least in part, the prevalence of $\mathrm{p} 16^{\mathrm{INK} 4 \mathrm{a}}$ loss over Rb1 loss in NSCLC.

In addition, loss of $R b 1$ appears particularly predominant in tumors originated from neural or NE cells, in line

Table 2. Tumor Phenotypes in Conditional Transgenic Mice

\begin{tabular}{|c|c|c|c|c|c|c|c|}
\hline Genotype & $\begin{array}{l}\text { Number } \\
\text { of mice }\end{array}$ & $\begin{array}{c}\text { No lesions } \\
(\%)\end{array}$ & $\begin{array}{c}\text { Only SCLC } \\
(\%)\end{array}$ & $\begin{array}{c}\text { Only NSCLC } \\
(\%)\end{array}$ & $\begin{array}{l}\text { SCLC and } \\
\text { NSCLC }(\%)\end{array}$ & $\begin{array}{l}\text { Other lesions } \\
(\%)\end{array}$ & $\begin{array}{l}\text { Latency } \\
\text { (days) }\end{array}$ \\
\hline$R b F / F ; \operatorname{Trp} 53 F / F$ & 33 & - & 91 & - & 6 & 3 & $196-350$ \\
\hline$R b F / w t ; \operatorname{Trp} 53 F / F^{\mathrm{a}}$ & 13 & $46.1^{\mathrm{c}}$ & 38.5 & 7.6 & 7.6 & - & $331-584$ \\
\hline$R b F / F ; \operatorname{Trp} 53 F / w t^{\mathrm{b}}$ & 13 & $38.5^{\mathrm{c}}$ & - & 7.6 & 38.5 & 15.4 & $308-588$ \\
\hline$R b F / F$ & 8 & 100 & - & - & - & - & \\
\hline $\operatorname{Trp} 53 F / F$ & 6 & - & - & 100 & - & - & $350-530$ \\
\hline$L S L-K-R a s V 12$ & 12 & - & - & 100 & - & - & 63-91 \\
\hline
\end{tabular}

${ }^{\mathrm{a}} \mathrm{LOH}$ in Rb1 was observed in all SCLC tumors tested from heterozygous mice, whereas the wt Rb1 allele was retained in NSCLC lesions.

${ }^{\mathrm{b}} \mathrm{LOH}$ in Trp53 was observed in all lesions tested, regardless of the tumor phenotype.

'These mice were sacrificed at early time points either for examination or due to non-tumor-related sickness. 
with the continued expression of neuronal markers including Ascl1 in the majority of these tumors. Whether or not Ascl1 is a direct or indirect downstream effector of $\mathrm{Rb1}$ 's NE-fate restrictive function, it is clearly necessary to sustain the NE differentiation in human SCLC cell lines (Borges et al. 1997). In fact, Ascl1 immunoreactivity was observed in most mSCLC, and expression levels at the protein and RNA levels correlate very well with the $\mathrm{NE}$ differentiation of mSCLC-derived cell lines (Fig. 4).

Also intriguing are our observations regarding L-myc gene (Lmycl) copy number and expression. Array CGHBAC of primary mSCLC tumor material invariably showed amplification of a narrow genomic stretch containing the Lung carcinoma derived myc gene (Lmyc1). Even more interestingly, most, if not all, cell clones showing NE phenotype also have a gain in the Lmycl gene copy number, whereas this amplicon is not observed in non-NE-related cell clones (Fig. 4). Expression array data are completely consistent with this finding, as a high level of L-myc expression is observed in mSCLC primary tumors and NE cell clones, but not in non-NE cells. Whether or not Lmycl amplification is functionally responsible for aspects of the NE differentiation, e.g., directly or indirectly regulating Ascll expression, is a question that needs to be addressed in future experiments.

In any case, this confirms that different cell populations in the tumor can harbor distinct genetic alterations, determining or at least correlating with phenotypic divergence. Of note, analysis of whole tumor preparations may neglect the existence of small populations of variant cells that represent a minor component within the tumor. The contribution of these cells to the properties of the tumor (invasion, metastasis, drug resistance) might be easily underestimated, and deserves further study.

\section{CONCLUSIONS}

The sporadic mouse SCLC model generated by conditional deletion of Trp53 and $R b 1$ tumor suppressor genes in the mouse lung epithelium has proven to be an invaluable tool for the understanding of neuroendocrine tumor biology because (1) it mimics the histological and pathological characteristics of human SCLC; (2) it presents with a high penetrance, specificity, and relatively short latency; (3) it reproduces some of the additional genetic aberrations and expression changes observed in the human counterpart (i.e., MYCL1 amplification, ASCL1 upregulation); (4) potential target cells and early lesions can be studied; (5) cell lines can be derived and subcloned without being perturbed by major culture artifacts; and (6) derived cell clones may reflect different steps in the tumorigenic process and enable us to establish detailed genotype-phenotype correlations.

Applying the approach described, we can gain a detailed insight into the events that determine tumor phenotype and prognosis. First, we want to define which additional genetic aberrations are necessary for tumor formation and maintenance, as well as when and why these lesions are selected. What is the reason for specific amplification of Lmycl among other Myc family mem- bers? Second, we want to dissect the signaling pathways that sustain tumor growth, with special interest in the paracrine loops that establish cross-talk relations between cells in a tumor. Finally, we want to assess why distinct populations of cells with different genotypes do persist in the tumor mass. For instance, non-NE cells seem to have little advantage compared to NE cells within the SCLC tumor, but they might contribute to tumor growth by providing growth factors, cytokines, or extracellular matrix components. In addition, this minor cell population can serve as a source of plasticity giving the tumor better chances to adapt to new conditions, like hypoxia, nutrient depletion, or chemotherapy. To test these possibilities further in vivo, we are currently testing the advantage of mixed populations versus pure cloned populations in orthotopically grafted mice.

However, the final goal of any animal model for human pathology is to translate the acquired knowledge into prevention, diagnostic, or treatment strategies, as well as to enable preclinical testing of such strategies. The mSCLC model also offers good opportunities for translational studies. The search for serological markers in mice in early stages of the disease can provide a tool for early detection of lung neuroendocrine lesions. On the other hand, intervention studies using the in vitro and in vivo systems described here can yield new preventive or therapeutic regimens. For example, RNA interference technology applied to cloned cell lines either in vitro or in tumor cell grafts will enable us to test candidate targets even before having target-specific drugs. In addition, cloned cell lines can be labeled with reporter genes (e.g., luciferase, lacZ) to facilitate the longitudinal screening of tumor growth and metastatic spread.

These studies, together with observations made in other mouse tumor models, will undoubtedly increase our understanding not only of cancer as a disease, but also of the selective processes leading to tumor progression. In addition to the mSCLC model, we have generated a number of different well-defined mouse tumor models, like lung adenocarcinoma (Meuwissen et al. 2001), mesothelioma (J. Jongsma et al., in prep.), or melanoma (I. Huijbers et al., in prep.) also showing an important degree of specificity. The goal is now to uncover the Achilles' heel of these tumorigenic processes so that we can intervene in a way that leaves little chance for tumor progression or relapse.

\section{ACKNOWLEDGMENTS}

The authors thank Suzanne Jonkheer and John Zevenhoven for technical assistance, and the personnel of the mouse facility for animal care. J.C. was supported by the Centre of Biomedical Genetics. Part of the work was supported by The Dutch Cancer Society (E.vM.).

\section{REFERENCES}

Ball D.W., Azzoli C.G., Baylin S.B., Chi D., Dou S., Donis-Keller H., Cumaraswamy A., Borges M., and Nelkin B.D. 1993. Identification of a human achaete-scute homolog highly expressed in neuroendocrine tumors. Proc. Natl. Acad. Sci. 90: 5648. 
Bernards R. and Weinberg R.A. 2002. A progression puzzle. Nature 418: 823.

Borges M., Linnoila R.I., van de Velde H.J., Chen H., Nelkin B.D., Mabry M., Baylin S.B., and Ball D.W. 1997. An achaetescute homologue essential for neuroendocrine differentiation in the lung. Nature 386: 852.

Brambilla E., Negoescu A., Gazzeri S., Lantuejoul S., Moro D., Brambilla C., and Coll J.L. 1996. Apoptosis-related factors p53, Bcl2, and Bax in neuroendocrine lung tumors. Am.J. Pathol. 149: 1941.

Brambilla E., Moro D., Gazzeri S., Brichon P.Y., Nagy-Mignotte H., Morel F., Jacrot M., and Brambilla C. 1991. Cytotoxic chemotherapy induces cell differentiation in small-cell lung carcinoma. J. Clin. Oncol. 9: 50.

Dean M., Fojo T., and Bates S. 2005. Tumour stem cells and drug resistance. Nat. Rev. Cancer 5: 275.

Dosaka-Akita H., Hu S.X., Fujino M., Harada M., Kinoshita I., Xu H.J., Kuzumaki N., Kawakami Y., and Benedict W.F. 1997. Altered retinoblastoma protein expression in nonsmall cell lung cancer: Its synergistic effects with altered ras and $\mathrm{p} 53$ protein status on prognosis. Cancer 79: 1329.

Fathi Z., Way J.W., Corjay M.H., Viallet J., Sausville E.A., and Battey J.F. 1996. Bombesin receptor structure and expression in human lung carcinoma cell lines. J. Cell. Biochem. Suppl. 24: 237.

Fong K.M., Sekido Y., Gazdar A.F., and Minna J.D. 2003. Lung cancer. 9: Molecular biology of lung cancer: Clinical implications. Thorax 58: 892 .

Forgacs E., Zochbauer-Muller S., Olah E., and Minna J.D. 2001. Molecular genetic abnormalities in the pathogenesis of human lung cancer. Pathol. Oncol. Res. 7: 6.

Giangreco A., Reynolds S.D., and Stripp B.R. 2002. Terminal bronchioles harbor a unique airway stem cell population that localizes to the bronchoalveolar duct junction. Am. J. Pathol. 161: 173.

Guerra C., Mijimolle N., Dhawahir A., Dubus P., Barradas M., Serrano M., Campuzano V., and Barbacid M. 2003. Tumor induction by an endogenous K-ras oncogene is highly dependent on cellular context. Cancer Cell 4: 111.

Harris H. 2004. Tumour suppression: Putting on the brakes. $\mathrm{Na}$ ture 427: 201.

Hong K.U., Reynolds S.D., Giangreco A., Hurley C.M., and Stripp B.R. 2001. Clara cell secretory protein-expressing cells of the airway neuroepithelial body microenvironment include a labelretaining subset and are critical for epithelial renewal after progenitor cell depletion. Am. J. Respir. Cell Mol. Biol. 24: 671.

Hong K.U., Reynolds S.D., Watkins S., Fuchs E., and Stripp B.R. 2004. Basal cells are a multipotent progenitor capable of renewing the bronchial epithelium. Am. J. Pathol. 164: 577.

Hynes R.O. 2003. Metastatic potential: Generic predisposition of the primary tumor or rare, metastatic variants-or both? Cell 113: 821.

Jackson E.L., Willis N., Mercer K., Bronson R.T., Crowley D., Montoya R., Jacks T., and Tuveson D.A. 2001. Analysis of lung tumor initiation and progression using conditional expression of oncogenic K-ras. Genes Dev. 15: 3243.

Johnson L., Mercer K., Greenbaum D., Bronson R.T., Crowley D., Tuveson D.A., and Jacks T. 2001. Somatic activation of the K-ras oncogene causes early onset lung cancer in mice. Nature 410: 1111.

Jonkers J. and Berns A. 2002. Conditional mouse models of sporadic cancer. Nat. Rev. Cancer 2: 251.

Kang Y., Siegel P.M., Shu W., Drobnjak M., Kakonen S.M., Cordon-Cardo C., Guise T.A., and Massague J. 2003. A multigenic program mediating breast cancer metastasis to bone. Cancer Cell 3: 537.

Kim C.F., Jackson E.L., Woolfenden A.E., Lawrence S., Babar I., Vogel S., Crowley D., Bronson R.T., and Jacks T. 2005. Identification of bronchioalveolar stem cells in normal lung and lung cancer. Cell 121: 823.

Kraus A.C., Ferber I., Bachmann S.O., Specht H., Wimmel A., Gross M.W., Schlegel J., Suske G., and Schuermann M. 2002.
In vitro chemo- and radio-resistance in small cell lung cancer correlates with cell adhesion and constitutive activation of AKT and MAP kinase pathways. Oncogene 21: 8683.

Landis S.H., Murray T., Bolden S., and Wingo P.A. 1999. Cancer statistics, 1999. CA Cancer J. Clin. 49: 8.

Maulik G., Kijima T., and Salgia R. 2003. Role of receptor tyrosine kinases in lung cancer. Methods Mol. Med. 74: 113.

Meuwissen R. and Berns A. 2005. Mouse models for human lung cancer. Genes Dev. 19: 643.

Meuwissen R., Linn S.C., van der Valk M., Mooi W.J., and Berns A. 2001. Mouse model for lung tumorigenesis through Cre/lox controlled sporadic activation of the K-Ras oncogene. Oncogene 20: 6551.

Meuwissen R., Linn S.C., Linnoila R.I., Zevenhoven J., Mooi W.J., and Berns A. 2003. Induction of small cell lung cancer by somatic inactivation of both $\operatorname{Trp} 53$ and $\mathrm{Rb} 1$ in a conditional mouse model. Cancer Cell 4: 181.

Minn A.J., Kang Y., Serganova I., Gupta G.P., Giri D.D., Doubrovin M., Ponomarev V., Gerald W.L., Blasberg R., and Massague J. 2005. Distinct organ-specific metastatic potential of individual breast cancer cells and primary tumors. J. Clin. Invest. 115: 44

Paez J.G., Janne P.A., Lee J.C., Tracy S., Greulich H., Gabriel S., Herman P., Kaye F.J., Lindeman N., Boggon T.J., Naoki K., Sasaki H., Fujii Y., Eck M.J., Sellers W.R., Johnson B.E., and Meyerson M. 2004. EGFR mutations in lung cancer: Correlation with clinical response to gefitinib therapy. Science 304: 1497.

Ramaswamy S., Ross K.N., Lander E.S., and Golub T.R. 2003. A molecular signature of metastasis in primary solid tumors. Nat. Genet. 33: 49.

Reissmann P.T., Koga H., Takahashi R., Figlin R.A., Holmes E.C., Piantadosi S., Cordon-Cardo C., and Slamon D.J. 1993. Inactivation of the retinoblastoma susceptibility gene in nonsmall-cell lung cancer. The Lung Cancer Study Group. Oncogene 8: 1913 .

Richardson G.E. and Johnson B.E. 1993. The biology of lung cancer. Semin. Oncol. 20: 105.

Rozengurt E. 1998. V. Gastrointestinal peptide signaling through tyrosine phosphorylation of focal adhesion proteins. Am. J. Physiol. 275: G177.

Schmidt-Kittler O., Ragg T., Daskalakis A., Granzow M., Ahr A., Blankenstein T.J., Kaufmann M., Diebold J., Arnholdt H., Muller P., Bischoff J., Harich D., Schlimok G., Riethmuller G., Eils R., and Klein C.A. 2003. From latent disseminated cells to overt metastasis: Genetic analysis of systemic breast cancer progression. Proc. Natl. Acad. Sci. 100: 7737.

Toyooka S., Tsuda T., and Gazdar A.F. 2003. The TP53 gene, tobacco exposure, and lung cancer. Hum. Mutat. 21: 229.

van de Vijver M.J., He Y.D., van't Veer L.J., Dai H., Hart A.A., Voskuil D.W., Schreiber G.J., Peterse J.L., Roberts C., Marton M.J., Parrish M., Atsma D., Witteveen A., Glas A., Delahaye L., van der Velde T., Bartelink H., Rodenhuis S., Rutgers E.T., Friend S.H., and Bernards R. 2002. A gene-expression signature as a predictor of survival in breast cancer. N. Engl. J. Med. 347: 1999.

van 't Veer L.J., Dai H., van de Vijver M.J., He Y.D., Hart A.A., Mao M., Peterse H.L., van der Kooy K., Marton M.J., Witteveen A.T., Schreiber G.J., Kerkhoven R.M., Roberts C., Linsley P.S., Bernards R., and Friend S.H. 2002. Gene expression profiling predicts clinical outcome of breast cancer. Nature 415: 530 .

Watkins D.N., Berman D.M., Burkholder S.G., Wang B., Beachy P.A., and Baylin S.B. 2003. Hedgehog signalling within airway epithelial progenitors and in small-cell lung cancer. Nature 422: 313

Wikenheiser-Brokamp K.A. 2004. Rb family proteins differentially regulate distinct cell lineages during epithelial development. Development 131: 4299.

Worden F.P. and Kalemkerian G.P. 2000. Therapeutic advances in small cell lung cancer. Expert Opin. Investig. Drugs 9: 565.

Zochbauer-Muller S., Gazdar A.F., and Minna J.D. 2002. Molecular pathogenesis of lung cancer. Annu. Rev. Physiol. 64: 681. 


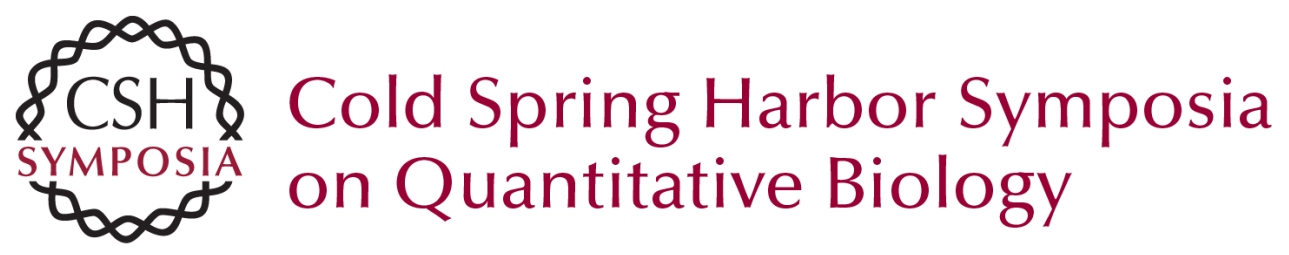

\section{Genotype-Phenotype Relationships in a Mouse Model for Human Small-Cell Lung Cancer}

J. CALBÓ, R. MEUWISSEN, E. VAN MONTFORT, et al.

Cold Spring Harb Symp Quant Biol 2005 70: 225-232

Access the most recent version at doi:10.1101/sqb.2005.70.026

References This article cites 41 articles, 8 of which can be accessed free at:

http://symposium.cshlp.org/content/70/225.full.html\#ref-list-1

License

Email Alerting Receive free email alerts when new articles cite this article - sign up in

Service the box at the top right corner of the article or click here. 